\title{
Influence of Time and Intensity of Pruning on Growth and Flowering Behaviour of Cut Rose
}

\author{
Deb Raj Adhikari ${ }^{1}$, D.R. Baral ${ }^{2}$, D.M. Gautam ${ }^{2}$ and U.K. Pun ${ }^{3}$ \\ ${ }^{1}$ District Agriculture Development Office, Sindhuli, Nepal \\ ${ }^{2}$ Agriculture and Forestry University, Rampur, Chitwan, Nepal \\ ${ }^{3}$ Himalayan Flora, Lalitpur, Nepal \\ E-mail: adhikari.debraj@gmail.com
}

\begin{abstract}
A field investigation was carried out during July 2008 to April 2009 in a farmer's field at Gunjanagar-5, Chitwan, Nepal to evaluate the influence of time and intensity of pruning on growth and flowering behaviour of cut rose cv. Super Tata (Rosa hybrida). The experiment was laid out in a completely randomized block design with nine treatment combinations and replicated thrice. The treatments comprised of three dates of pruning i.e. $30^{\text {th }} \mathrm{July}, 15^{\text {th }}$ August and $30^{\text {th }}$ August and three pruning intensities i.e. heavy ( 6 buds per plant), medium (12 buds per plant) and light (18 buds per plant). Both time and intensity of pruning significantly affected growth and yield attributing parameters. The plants pruned heavily on $30^{\text {th }}$ July produced highest plant height, number, length and diameter of canes. Similarly, stem bud as well as floral initiation were also earlier as compared to other treatments. On the other hand, fresh and dry weight of leaf and leaf area index were highest from the plants pruned heavily on $15^{\text {th }}$ August. Flower stem diameter was higher in July $30^{\text {th }}$ pruned rose plants while, flower stem length was found longer $(47.67 \mathrm{~cm})$ in August $15^{\text {th }}$ pruned ones. Heavily pruned plants produced earlier floral initiation (45.48 days). Flower stem length $(50.33 \mathrm{~cm})$ and diameter $(0.60 \mathrm{~cm})$, length $(2.91 \mathrm{~cm})$ and diameter $(2.29 \mathrm{~cm})$ of floral buds were found highest from heavily pruned plants. Number of flowers per plant was recorded higher (22) from earlier ( $30^{\text {th }} \mathrm{July}$ ) and lightly pruned rose plants. The longest duration of flowering (212.8 days) was observed from earlier and heavily pruned (198.1 days) plants. Sequential pruning can produce rose flowers at desired time.
\end{abstract}

Key words: time of pruning, intensity of pruning, flower production

\section{Introduction}

Rose is a symbol of beauty, fragrance and is used to convey the message of love (Arora 2007). Rose is one of the nature's beautiful creations and is universally acclaimed as the Queen of Flower (Yadav et al. 1989). The demand of rose cut flower is 7000-9000 sticks per day in Kathmandu and about 14.1 ha land is covered under rose cultivation (FAN 2013). Pruning is a major horticultural practice in rose cultivation (Edmond et al. 1994). Pruning is an invigorating process calculated to produce a definite effect in the formation of shoots, flowers, fruits and roots (Gopalaswamiengar 1970). The kind and severity of pruning of the rose depends on the kind of rose grown and the size of the flower desired. Different dates of pruning seem to have influence on flower yield and quality subsequently (Mukhophadhyay 1990). Pruning of rose plants at different dates was helpful in staggering the harvest of cut flowers. The severity of pruning has considerable influence both on vegetative growth and flower production. Depending upon the extent and level of shortening the stem, there are three types of pruning - light, moderate and heavy (Dhua 1999).Several researchers have reported increased flower production with light pruning and quality blooms with severe pruning.

Flower production is highly technical. Lack of knowledge on these aspects leads to poor quality of 
the produce and also increases the cost. Farmers get very low price of their produces. Availability of cut flower in market is low in quality as well as in quantity. There is no standard time and intensity of pruning for the market oriented quality rose production in Nepal. Therefore, this research was conducted to determine the optimum time and intensity of rose pruning for efficient growth, yield and quality of cut flower.

\section{Methodology}

A field experiment was laid out in a year old rose plant of the commonly grown Super Tata having yellow color flower was chosen as a test crop for the experiment. The treatment combinations of time and intensity of pruning were selected as treatments. There were nine plants in each experimental plot. Observations were taken from three middle plants. Individual plants were pruned three times at 15 days interval July 30, August 15 and August 30, 2008 to different intensities - 6, 12 and 18 buds in each plant. The field experiment was laid out in a completely randomized block design having two factors with nine treatment combinations replicated thrice.

The rose plants were pruned to allow the intensity as desired. After pruning, the cut ends were painted with a fungicide paste (Bordeaux paint). All the intercultural operations like hoeing, weeding, topdressing, irrigation, earthing up, mulching were done regularly. Flowers were harvested from November, 2008 to April, 2009 manually during evening retaining $10-12 \mathrm{~cm}$ stem from the branch attachment. Observations were recorded for several vegetative characters such as plant height, cane characteristics, days to stem bud initiation, leaf characteristics and yield attributing parameters like days to floral initiation, flower stem characteristics, flower bud characteristics, fresh and dry weight of flower stem, numbers of petals per flower, number of flower production and duration of flowering. Data obtained were tabulated and analyzed by using statistical software package MSTAT. Mean comparison, F test and other possible analyse and interpretation were made.

\section{Results and Discussion}

\section{Plant height}

Statistical analysis result showed that the increment in plant height of rose plant was higher in the plants pruned on July 30 followed by August 15 and 30 respectively. The plant height was highest in lightly pruned rose plants.

\section{Cane characteristics}

There was progressive increment in number of canes per plant and length of cane with decrease in severity of pruning. Lightly pruned rose plants showed highest number of canes (3.18) and longest length of cane $(15.09 \mathrm{~cm})$ which significantly differed with the heavily pruned ones which showed lowest number of canes (2.48) per plant and shortest length of cane $(8.53 \mathrm{~cm})$ (Table 1). It might obviously be that the higher the number of buds in a cane, the length of it increased. Heavily pruned rose plant showed highest cane diameter $(1.07 \mathrm{~cm})$ which significantly differed with the lightly pruned plants $(0.78 \mathrm{~cm})$ (Table 1$)$. Pinkard and Beadle (2000) also noted increased branch diameter with increased severity of pruning.

Table 1. Effect of time of pruning on cane characteristics of cut rose cv. Super Tata in Chitwan (2008/09)

\begin{tabular}{l|c|c|c}
\hline \multirow{2}{*}{ Treatments } & \multicolumn{3}{|c}{ Cane characte ristics } \\
\cline { 2 - 4 } & No. of canes & Length of canes (cm) & Diameter of canes (cm) \\
Intersity of pruning & & & $1.07 \mathrm{a}$ \\
6 buds & $2.48 \mathrm{c}$ & $8.53 \mathrm{c}$ & $0.87 \mathrm{~b}$ \\
12 buds & $2.81 \mathrm{~b}$ & $11.56 \mathrm{~b}$ & $0.78 \mathrm{~b}$ \\
18 buds & $3.18 \mathrm{a}$ & $15.09 \mathrm{a}$ & 15.73 \\
CV\% & 10.64 & 17.21 & \\
\hline
\end{tabular}

${ }^{a}$ Means in the column followed by same letter in each treatment do not differ significantly at ( $\left.\mathrm{p}=0.05\right)$ by DMRT. $\mathrm{SEM}=$ Standard error of mean, $\mathrm{LSD}=$ Least significant difference and $\mathrm{CV}=$ Coffficient of variance

Days to first stem bud initiation

Pruning on July 30 recorded the earliest days to first bud initiation (3.60 days) followed by August 15 and
August 30 (Table 2). This might be due to the effect of temperature. The findings of Mukhopadhyay (1990) for stem bud initiation were in conformity with present 
D. Adhikari et al./nfluence of Time and Intensity........

finding. The earliest days to first bud initiation $(3.85$ days) was recorded from heavily pruned rose plant followed by medium and light pruning. This result agrees with Bajwa et al., (1998) who also observed similar results that more severe was the pruning the faster was the growth rate of the stem bud. This might be due to the availability of carbohydrate reserve for the metabolic activities because in heavily pruned plants only few number of buds have to grow. The advantage obtained through pruning is the development of new vegetative shoots. Those shoots replenish the plant's carbohydrate reserves, also mature and bear flower. This advantage of pruning is also observed by Oosthuyse (1994).

Table 2. Effect of time and intensity of pruning on days to first stem bud initiation of cut rose cv. Super Tata in Chitwan (2008/09)

\begin{tabular}{l|l|l|l}
\hline \multicolumn{2}{c}{ Days to first ste m bud initiation } & \multicolumn{2}{c}{ Days to first ste m bud initiation } \\
\hline Time of pruning (Fa) & $3.59 \mathrm{c}$ & Inte nsity of pruning (Fb) & $3.85 \mathrm{c}$ \\
July 30 & $4.14 \mathrm{~b}$ & $6 \mathrm{buds}$ & $4.11 \mathrm{~b}$ \\
August 15 & $4.63 \mathrm{a}$ & $12 \mathrm{buds}$ & $4.40 \mathrm{a}$ \\
August 30 & 5.86 & $18 \mathrm{buds}$ & 5.86 \\
CV\% & $\mathrm{CV} \%$ & \\
\hline
\end{tabular}

${ }^{a}$ Means in the column followed by same letter in each treatment do not differ significantly at ( $\left.\mathrm{p}=0.05\right)$ by DMRT. SEM=Standard error of mean, $\mathrm{LSD}=$ Least significant difference and $\mathrm{CV}=$ Coffficient of variance

\section{Leaf characteristics}

Pruning affects leaf morphology, but the responses depend on the severity of pruning. Increasing severity of pruning is associated with leaves often becoming larger, thereby increasing the surface area available for light interception and photosynthesis (Pinkard \& Beadle 1998). The fresh and dry weight of leaves from heavily pruned rose plants on August 15 was found highest (1.48 and $0.62 \mathrm{~g}$ ) which was at par with heavily pruned rose plants on July 30 and on August 30. Lightly pruned rose plants on August 15 recorded the lowest fresh and dry weight of leaves $(0.85$ and $0.34 \mathrm{~g})$ (Table 3). The heavily pruned rose plants on August 15 produced leaves having highest leaf area index while lightly pruned rose plants on August 15 produced leaves having lowest leaf area index.

Table 3. Interaction effect of time and intensity of pruning on leaf characteristics of cut rose cv. Super Tata in Chitwan (2008/09)

\begin{tabular}{c|c|c|c}
\hline Treatments & Fresh weight of leaves $(g)$ & Dry weight of leaves $(g)$ & Leaf area index \\
\hline Time and Inte nsity of pruning & $1.40 \mathrm{~b}$ & $0.61 \mathrm{a}$ & $569.90 \mathrm{~b}$ \\
July $30 \times 6$ buds & $1.22 \mathrm{c}$ & $0.56 \mathrm{~b}$ & $488.30 \mathrm{~d}$ \\
12 buds & $1.00 \mathrm{~d}$ & $0.40 \mathrm{~d}$ & $363.90 \mathrm{~g}$ \\
18 buds & $1.48 \mathrm{a}$ & $0.62 \mathrm{a}$ & $607.80 \mathrm{a}$ \\
Aug. $15 \times 6$ buds & $1.17 \mathrm{c}$ & $0.51 \mathrm{c}$ & $480.50 \mathrm{~d}$ \\
12 buds & $0.85 \mathrm{e}$ & $0.34 \mathrm{e}$ & $344.50 \mathrm{~h}$ \\
18 buds & $1.23 \mathrm{c}$ & $0.58 \mathrm{~b}$ & $505.70 \mathrm{c}$ \\
Aug. $30 \times 6$ buds & $0.95 \mathrm{~d}$ & $0.35 \mathrm{e}$ & $426.80 \mathrm{e}$ \\
12 buds & $0.85 \mathrm{e}$ & $0.35 \mathrm{e}$ & $405.60 \mathrm{f}$ \\
CV\% & 3.50 & 3.66 & 1.52 \\
\hline
\end{tabular}

${ }^{a}$ Means in the column followed by same letter in each treatment do not differ significantly at ( $\left.\mathrm{p}=0.05\right)$ by DMRT. SEM=Standard error of mean, LSD=Least significant difference and CV=Coffficient of variance

\section{Floral initiation}

The earlier flower bud appearance (39.42 days), days to flower initiation (43.83 days) and days to $50 \%$ flower initiation (58.33 days) were recorded in rose plants pruned on July 30 and maximum duration for the floral initiation was recorded in rose plants pruned on August 30 (Fig. 1). The earlier flower bud initiation (40.75 days), days to flower initiation (46.96 days) and 
days to $50 \%$ flower initiation (60.78 days) (Fig. 2) was recorded in rose plants pruned retaining 6 buds per plant and maximum days for the floral initiation was recorded in rose plants pruned retaining 18 buds per plant. The more serve was the pruning the faster was the flower initiation which might be due to the earlier growth of stem bud and availability of nutrients. Similar results were found by Sharma et al. (1985).

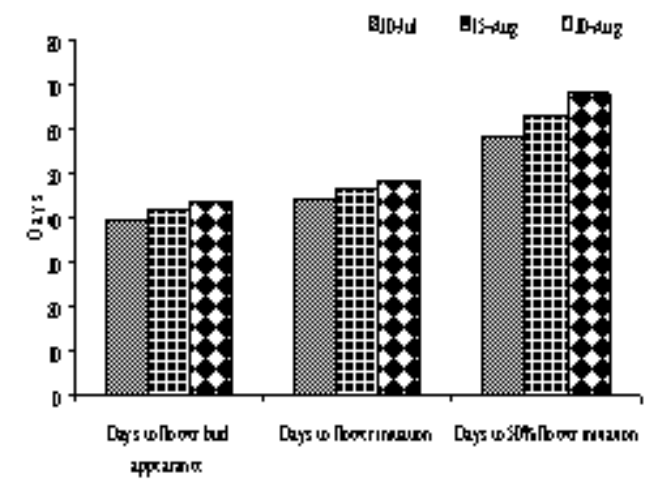

Fig. 1. Effect of time of pruning on days to flower bud appearance, days to flower initiation and days to $50 \%$ flower initiation of cut rose cv. Super Tata in Chitwan (2008/09)

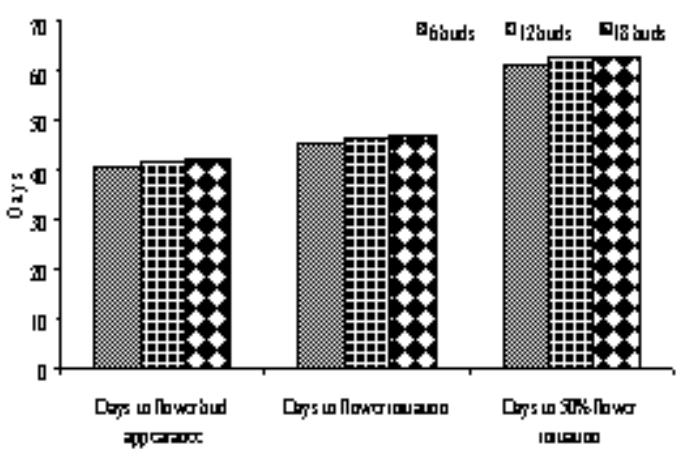

Fig. 2. Effect of intensity of pruning on days to flower bud appearance, days to flower initiation and days to $50 \%$ flower initiation of cut rose cv. Super Tata in Chitwan (2008/09)

\section{Flower stem}

The rose plants pruned on August 15 produced flowers having longest stem $(47.67 \mathrm{~cm})$ which was at par with the rose plants pruned on July $30(47.11 \mathrm{~cm})$ and shortest stem $(42.00 \mathrm{~cm})$ was produced from rose plants that were pruned on August 30 (Fig. 3) after harvest. Deepauw (1985) reported that the stem length of rose was only slightly affected by time of pruning.

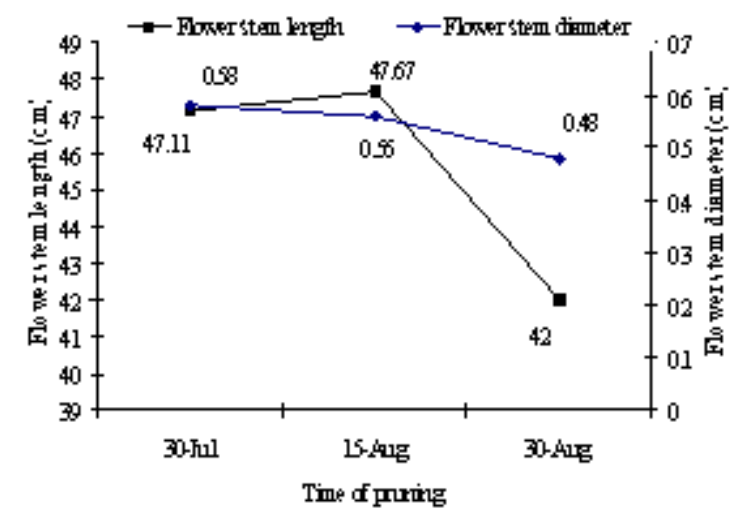

Fig. 3. Effect of time of pruning on flowerr stem length and flower stem diameter of cutt rose cv. Super Tata in Chitwan (2008/09)

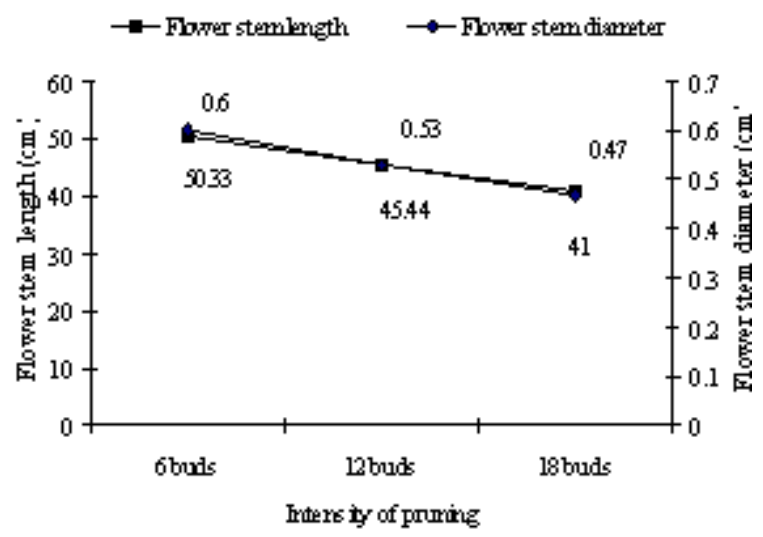

Fig. 4. Effect of intensity of pruning on flower stem length and flower stem diameter of cut rose cv. Super Tata in Chitwan (2008/09)

The rose plants pruned retaining 6 buds produced flowers having longest stem $(50.33 \mathrm{~cm})$ whereas shortest stem $(41.00 \mathrm{~cm})$ was produced from plants pruned retaining 18 buds (Fig. 4). The rose plants pruned on July 30 produced flowers having highest stem diameter $(0.58 \mathrm{~cm})$ and smallest stem diameter $(0.48 \mathrm{~cm})$ was produced from plants pruned on August 30 (Fig. 3). Fig. 4 showed that the rose plants pruned retaining 6 buds produced flowers having highest stem diameter $(0.60 \mathrm{~cm})$ and smallest stem diameter $(0.47 \mathrm{~cm})$ was produced from plants pruned retaining 18 buds.

This might be due to the availability of more nutrients to each stem on rose plants that were under heavy pruning than light pruning. Similar result was found 
by Bajwa et al. (1998). The increase in flower stem length and diameter may be due to lesser number of stem produced and therefore, more nutrients were available to heavily pruned rose plants. Similar results were reported by Bajawa and Sarowa (1977) and Gupta and Singh (1987).

\section{Flower bud characteristics}

The rose plants pruned retaining 6 buds produced flowers having highest flower bud length $(2.91 \mathrm{~cm})$ and diameter $(2.29 \mathrm{~cm})$ whereas smallest flower bud length and diameter $(2.23 \mathrm{~cm}$ and $1.90 \mathrm{~cm})$ was produced from rose plants pruned retaining 18 buds(Table 4). Higher amount of carbohydrates available for individual flower stem in heavily pruned plants might have contributed to better vigor of plants having longer and bigger flower bud. Mukhopadhyay et al. (1987) also agreed with these results.

Table 4. Effect of intensity of pruning on flower bud characteristics of cut rose flower cv. Super Tata in Chitwan (2008/09)

\begin{tabular}{l|c|c}
\hline & \multicolumn{2}{|c}{ Flower bud characte ristics } \\
\hline Treatrnents & $\begin{array}{c}\text { Length of flower } \\
\text { bud(cm) }\end{array}$ & $\begin{array}{c}\text { Diameter of } \\
\text { flower bud(cm) }\end{array}$ \\
\hline 6 buds & $2.911 \mathrm{a}$ & $2.298 \mathrm{a}$ \\
12 buds & $2.578 \mathrm{~b}$ & $2.043 \mathrm{~b}$ \\
18 buds & $2.233 \mathrm{c}$ & $1.900 \mathrm{c}$ \\
CV\% & 10.92 & 6.72 \\
\hline
\end{tabular}

${ }^{\mathrm{a}}$ Means in the column followed by same letter in each treatment do not differ significantly at $(\mathrm{p}=0.05)$ by DMRT. $\mathrm{SEM}=$ Standard error of mean, LSD=Least significant difference and $\mathrm{CV}=$ Coffficient of variance

Number of flowers and duration of flowering Early pruned plants (July 30) produced highest number of cut rose flowers (15.11) and longest duration of flowering (212.8 days) followed by plants pruned on August 15 (13.56) and (196.4 days) and rose plants pruned on August 30 (12.67 flowers) and (178.7 days) respectively (Fig. 5). The earlier pruned rose plants started to initiate flower stem buds earlier and flowering than later pruned rose plants but, the cessation of flowering was at similar time. Thus, the duration of flowering was found longer in early pruned rose plants on July 30. These result also agreed by Mukhopadhayay (1990). Deepauw (1985) observed that later was the pruning date, lower was the flower yield.
Heavily pruned rose plant produced lowest numbers of cut rose flowers (8.66) followed by medium pruned plant (13.00) whereas highest numbers of cut rose flowers (19.67) were produced by lightly pruned rose plant. Several workers have been reported increased flower production with light pruning and quality blooms with severe pruning (El. Gamassy et al. 1980, Irulappam et. al. 1993). Heavily pruned rose plant produced cut rose flowers for longest duration (198.1 days) followed by medium pruned plant (196.0 days) and shortest duration of flowering (193.8 days) were reported from lightly pruned rose plant (Fig. 6).

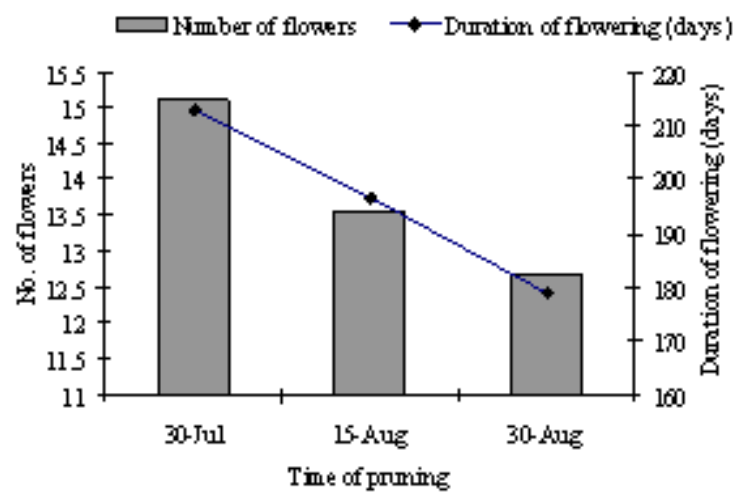

Fig. 5. Effect of time of pruning on number of flowers and duration of flowering of cut rose cv. Super Tata in Chitwan (2008/09)

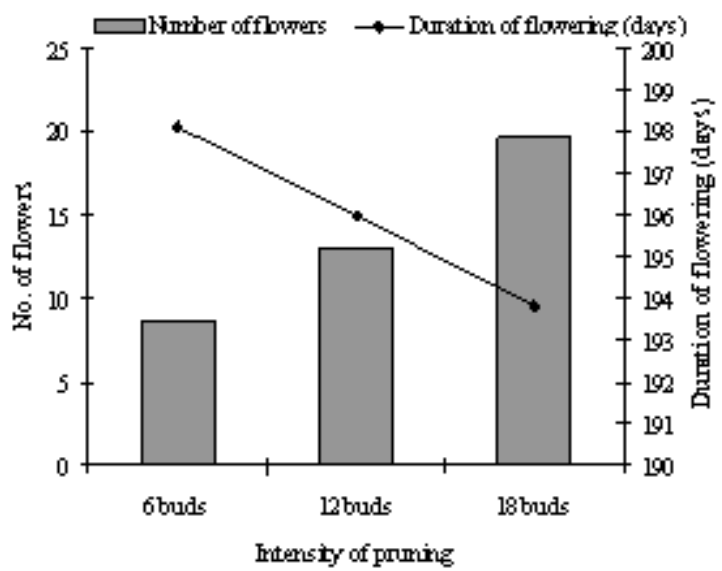

Fig. 6. Effect of intensity of pruning on number of flowers and duration of flowering of cut rose cv. Super Tata in Chitwan (2008/09)

Heavily pruned plant produced lowest numbers of cut rose flowers (8.66) followed by medium pruned plant (13.00) whereas highest numbers of cut rose flowers 
(19.67) were produced by lightly pruned rose plant. Several workers were reported increased flower production with light pruning and quality blooms with severe pruning (El. Gamassy et al. 1980) and Irulappam et. al.1993). Heavily pruned plant produced cut rose flowers for longest duration (198.1 days) followed by medium pruned plant (196.0 days) and shortest duration of flowering (193.8 days) were reported from lightly pruned rose plant (Fig. 6 ).

Time of pruning affects all the vegetative growth and flowering parameters of rose. The early pruned (July 30) rose plants performed significantly better as compared to other dates of pruning in all aspects. Similarly, the performance of rose flowers was also found significantly different with various intensities of pruning. Among the three intensities, heavily pruned rose plants performed better in all vegetative growth and yield attributing characteristics but, number of flowers per plant was found highest in lightly pruned rose plants. This suggests that pruning of rose is an important aspect in cut flowers production. Sequential pruning can produce rose flowers at successive desired time. Grower should prune the plants heavily to produce quality cut flowers whereas higher quantity of rose flowers can be achieved by light pruning. In Chitwan condition, cut rose growers can prune their rose plants after rainy season to produce cut rose targeting festivals and marriage months leaving 10-12 buds in each plant for quantity and quality of cut flowers.

\section{Acknowledgement}

National Agriculture Research and Development Fund (NARDF), Kathmandu is highly acknowledged for financial support to attempt this study.

\section{References}

Arora, J. S. 2007. Introductory ornamental horticulture. Kalyani Publishers. India. Pp. 52-60.

Bajawa, G. S., H. S. Sandhu and J. S. Bal. 1998. Effect of different pruning intensities on growth, yield and quality of ber (Zizyphus mauritiana Lamk.). Hariyana J. Hort. Sci. 16 (1-3): 209-213.
Bajawa, M. S. and P. S. Sarowa. 1977. Training and pruning of ber. Punjab Hort. J. 17 (1-2): 52-53.

Deepauw, W. B. 1985. Effect of time of pruning on subsequent growth of greenhouse roses. Bull. Colorado Flowers Growers Assoc. 300: 1-3.

Dhua, R. S. 1999. Rose. In: Floriculture and landscaping. (Eds. T. K. Bose, R. G. Maiti, R. S. Dhua and P. Das). Naya Prokash, Calcutta, India. Pp. 368-405.

Edmond, J. B., T. L. Senn, F. S. Andrews and R. G. Halfacre. 1994. Fundamentals of horticulture. Tata McGrawHill Publishing Company Ltd. New Delhi, India. 304. pp.

El. Gamassy, A. S., El. Hakim and S. El. Shafie. 1980. Effect of October pruning and fertilization on flowering of 'Hoover' rose plants. Ann. Agric. Sci. Cairo. 5 (2): 159-70.

FAN 2013. Floriculture souvenir. Floriculture Association Nepal. Kathmandu, Nepal.

Gopalaswamiengar, K. S. 1970. Complete gardening in India. Kalyan Printers. Banglore, India. Pp.129-137.

Gupta, M. R. and S. Singh. 1987. Effect of pruning on the growth, yield and fruit quality in ber. Punjab Hort. J. 56 (1-2): 49-53.

Irulappam, I., S. Muthuswamy and C. M. Pappiah. 1993. Effect of severity and time of pruning on the flower yield in Edward Rose (Rosa bourboniana Desp). South Indian Hort. 31 (6): 305-6.

Mukhopadhyay, A., K. Sujata and K. P. Singh. 1987. Note on influence of different levels of pruning on growth and flowering of rose cv. 'Happyness'. The Indian Journal of Horticulture.

Mukhophadhyay, A. 1990. Effect of time of pruning in rose. The Indian Journal of Horticulture. Pp. 261264.

Oosthuyse, S. A. 1994. Pruning of sensation mango trees to maintain their size and effect on uniform and later flowering. South African Mango Growers'Association Yearbook 14: 1-5.

Pinkard, E. A. and C. L. Beadle. 1998. Above-ground biomass partitioning and crown architecture of Eucalyptus nitens Maiden Following green pruning. Canadian Journal of Forest Research. 28: 1419-1428.

Pinkard, E. A. and C. L. Beadle. 2000. A physiological approach to pruning. International Forestry Review. 2(4): 2000.

Sharma, K. K., J. S. Jawanda and M. P. Singh. 1985. Effect of different pruning intensities on the growth and flower yield of rose. Punjab Hort. J. 32: 53-57.

Yadav, L. P., N. K. Dadlani and R. S. Malik. 1989. Rose. In: Commercial Flowers (Eds. T. K. Bose and L. P. Yadav). Naya Prakosh. Culcutta-7, India. Pp.15-150. 